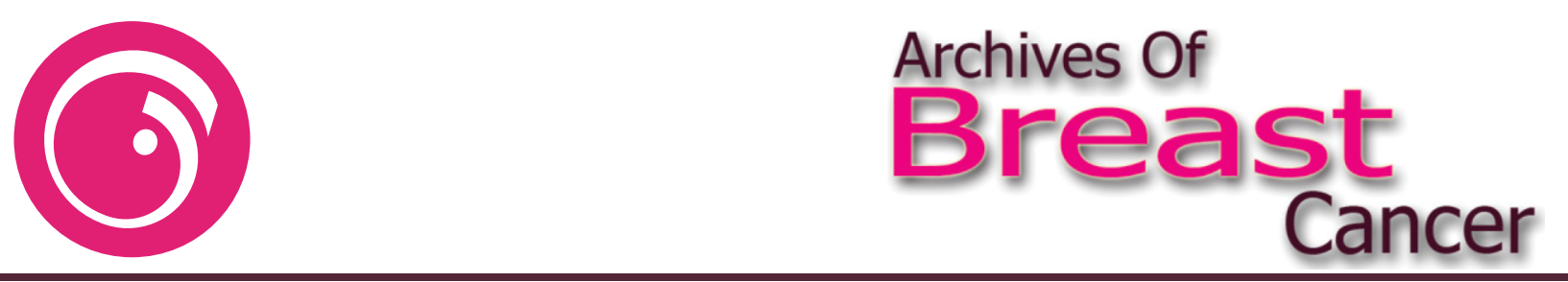

DOI: 10.32768/abc.202183210-215

\title{
Breast Cancer Awareness in Myanmar: Results of a Hospital-based Study in Mandalay
}

\author{
Myo Khin ${ }^{* a}$, San Shwe ${ }^{a}$, Khin May Oo ${ }^{a}$, Le-Le Win ${ }^{a}$ \\ ${ }^{a}$ Ministry of Health and Sports, Myanmar
}

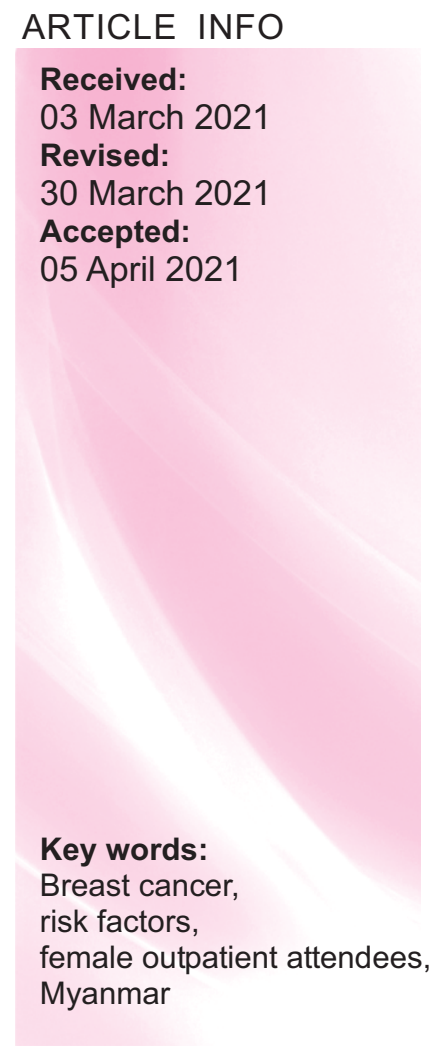

\section{Introduction}

Cancer is a leading cause of disease worldwide. The International Agency for Research on Cancer (IARC) has estimated that 19.3 million cancer cases and 9.96 million cancer deaths occurred globally in the year 2020. ${ }^{1}$ According to the World Health Organization (WHO), breast cancer is the most common cancer among women worldwide, claiming the lives of hundreds of thousands women each year and affecting countries at all levels of modernization. ${ }^{2}$

\footnotetext{
* Address for correspondence: Myo Khin, MBBS, MD(NSW), DCH, FRCP

Chair, Institutional Review Board No.1 Ministry of Health and Sports, Myanmar Email: khinmmaja@gmail.com
}

\section{ABSTRACT}

Background: Although breast cancer is an important health problem in anmar, awareness of breast health has not been widely described.

Methods: A cross-sectional descriptive study was carried out to explore awareness of early signs and risk factors of breast cancer among outpatient

Results: A total of 402 respondents with mean age of $31.4 \pm 9.0$ years participated in the study. More than half of the respondents $(65.9 \%)$ were aware of breast lumps as a breast cancer sign. Nearly half $(42 \%$ to $48.7 \%)$ of the respondents were aware of the various risk factors of breast cancer. Although 54.1\% had heard of breast self-examination, only $25.3 \%$ had knowledge of mammograms. Older women (age 49 years or more) had significantly better awareness of two early breast cancer signs; change of breast shape (54.1\% vs 39.9\%) and discharge from nipple (49.2\% vs 33.4\%). Those with less than high school education had significantly lower awareness of the following signs of breast cancer; thickening of the breast skin $(39.3 \%$ vs $20.45 \%)$, dimpling of the breast skin $(43.2 \%$ vs $24.6 \%)$, change of breast shape $(52.5 \%$ vs $35.2 \%)$, and discharge from nipple $(44.9 \%$ vs $31.9 \%)$. They also displayed significantly lower awareness of risk

Conclusion: Among the study respondents, only one third had heard of selfbreast examination and only a few (10\%) examined both breasts regularly. Greater awareness of breast health and breast cancer screening should be imparted to promote breast health among women in Myanmar.
It has also been estimated that over 2.1 million new cases of breast cancer occurred during 2018 with over 62 thousand deaths. ${ }^{3}$ Among the Asian countries, a higher mortality-to-incidence ratio, more advanced stage at diagnosis, and reduced survival was observed in less developed countries as compared developed countries. The crude rate of breast cancer incidence in Myanmar is also estimated at 22.9 per 100,000 women. ${ }^{4}$

Although breast cancer in Myanmar has been studied since the late 70 's ${ }^{5}$, little epidemiological data exists in Myanmar. Also, few studies have been conducted to address breast cancer awareness in Myanmar. A study on the awareness, knowledge and perceptions regarding common female cancers revealed that information regarding prevention and 
treatment of cervical and breast cancers needs to be promoted. ${ }^{6}$ A recent study showed that women living in rural Myanmar had inadequate information about breast cancer. $^{?}$

For control of diseases, effective health education programs need to be established. In the development of health education programs for control of breast cancer, it is very important to investigate the awareness of breast cancer among the indigenous female population of the country. We carried out the present study to examine the awareness of breast health and breast cancer among women in Myanmar attending the Central Women Hospital, Mandalay. We expect that the findings will contribute to the objectives of developing an appropriate program to promote awareness of breast cancer and increasing women's participation in breast cancer screening activities in Myanmar. The ultimate goal of the study is to reduce morbidity and mortality due to breast cancer among women in Myanmar.

\section{Methods}

\section{Study Design}

A hospital based cross-sectional descriptive study was carried out to assess the awareness of women regarding early signs of breast cancer and the risk factors.

\section{Study area and population}

The study was carried out during 2018 in the Central Women Hospital in Mandalay. Mandalay is situated in central Myanmar and is the secondlargest city after Yangon. It is the cultural capital of Myanmar, with a population of 1.2 million residents. The Central Women Hospital is the tertiary specialist hospital located in the center of Mandalay. The hospital is attended by women for antenatal care and for management of gynecological problems. Daily out-patient attendance is between 300 to 500 .

\section{Sampling}

Consecutive non-probability sampling method was used. Study respondents were those attending the hospital for different purposes related to women health and conditions (antenatal care, gynecological problems, etc.) Prior to the interview, the study objective was explained to the participants who were assured that all information would remain confidential and gave their informed consent. Recruitment was made until the required sample size was achieved.

\section{Sample size}

Considering the proportion of women having awareness of breast cancer at $38 \%{ }^{6}$, margin of error 0.05 , and non-response rate $10 \%$, the required sample size was 398 .

\section{Questionnaires and data analysis}

Self-administered questionnaires were used. One of the authors (SS) developed the questionnaire based on a valid and reliable questionnaire used in a previous epidemiological study carried out in Myanmar, in which structured questions regarding socio-demographic characteristics and awareness of common female cancers (breast and cervical cancers) were presented to 400 women. ${ }^{6}$ The questionnaires were arranged in two parts. Part one contained questions on demographic characteristics (age, marital status, education, and occupation). The second part comprised knowledge on symptoms of breast cancer, risk factors and screening tests. Data analyses were conducted with SPSS software version 16.0. Descriptive statistics (mean, SD for intervals, frequency with percentages for categorical variables) were calculated. Age and education levels were grouped for categorical analysis. To determine associations between categorical dependent variables, Chi-square tests were carried out. Data were shown as frequency/percentage for categorical variables and mean (standard deviation-SD) for continuous variables.

\section{Ethical Consideration}

Ethical approval was obtained from the Ethics Review Committee, Department of Medical Research, Ministry of Health and Sports. Written informed consent was obtained from all respondents after thorough explanation about the study.

\section{Results}

\section{Demographic characteristics}

A total of 402 respondents, aged 18 years to 67 years participated in the study. The mean age (SD) of the participants was $31.4 \pm 9.0$ years. Forty-two respondents $(10.5 \%)$ were single (never married), the remaining majority $(90 \%)$ were married (married, divorced or widowed). Concerning education, a few $(6.5 \%)$ of them had never attended school. All other participants had attended school and more than $118(29.6 \%)$ had studied at high school. Nearly half of them $(48.5 \%)$ were dependents (Table 1).

Awareness of early signs of breast cancer and screening for breast cancer

The majority of the respondents $(65.9 \%)$ were aware of lump as a breast cancer sign. Also, most of them recognized other early signs of breast cancer such as change of breast shape $(40.4 \%)$, discharge from nipple (35.8\%), dimpling of the breast skin $(30.1 \%)$, thickening of breast skin $(25.9 \%)$ and swelling of the breast $(24.6 \%)$. Very few were aware of soreness of breast $(20.3 \%)$ and redness of breast skin $(19.3 \%)$ as breast cancer signs. Also, the majority agreed to the fact that nulliparity $(48.7 \%)$, no breast feeding (48.7\%), lumps in breast (47.9\%), 
Table 1. Demographic characteristics of the respondents

\begin{tabular}{lcc}
\hline Characteristics of the respondents & \multicolumn{2}{c}{ Number } \\
\cline { 2 - 3 } & $\mathrm{N}$ & $\%$ \\
\hline Age & 36 & \\
18 to 20 years & 184 & 45.8 \\
21 to 30 years & 121 & 30.1 \\
31 to 40 years & 50 & 12.4 \\
41 to 50 years & 11 & 2.7 \\
51 years and above & & \\
Marital status & 42 & 10.5 \\
Single & 333 & 83 \\
Married & 12 & 3 \\
Divorced & 14 & 3.5 \\
Widowed & & \\
Education Level & 65 & 16.3 \\
Illiterate, Read \& Write & 108 & 26.8 \\
$\quad$ Primary & 109 & 27.3 \\
Middle & 65 & 16.3 \\
High & 53 & 13.3 \\
$\quad$ University/ Graduate & & \\
Occupation & 195 & 48.5 \\
Dependent/unemployed & 55 & 13.7 \\
Manual labors & 19 & 4.7 \\
$\quad$ Private employee & 37 & 9.2 \\
Government employee & 96 & 23.5 \\
Small own business & & \\
\hline
\end{tabular}

breast cancer history in family (46\%), and oral contraceptives $(42.0 \%)$ increase the risk of breast cancer. Nearly two-thirds of the respondents $(64 \%)$ had heard of breast cancer screening. Although half of them $(54.1 \%)$ had heard of breast selfexamination, only $25.3 \%$ had knowledge on mammograms.

\section{Marital status}

The study population included 341 married women and 41 never married women. We found no significant differences between the two groups on breast cancer awareness, knowledge of risk factors and on breast cancer screening.

\section{Age of the respondents}

The study population consisted of 41 respondents aged 40 years and above and 341 respondents younger than 40 years of age. Older women had significantly better knowledge of two early breast cancer signs; change of breast shape $(54.1 \%$ vs $37.9 \%, \mathrm{p}=0.023)$, and discharge from nipple $(49.2 \%$ vs $33.4 \%, \mathrm{p}=0.021$ ). Older women also knew better than the younger age group that breast lumps increased the risk of breast cancer $(59.0 \%$ vs $46.3 \%$, $\mathrm{p}=0.046$ ). There were no differences on other breast cancer signs, knowledge of risk factors and screening procedures between the two groups. Apart from knowledge of a few signs and on mammography, older women had more correct answers about the awareness of breast cancer (Table 2).

\section{Education status}

The education of the respondents played an important role in their awareness of breast cancer. In the present study, 282 respondents had less than high school education. They had significantly lower awareness of the following signs of breast cancer; thickening of the breast skin, dimpling of the breast skin, change of breast shape, and discharge from nipple. Those who had more than high school level of education (118 respondents) had significantly higher knowledge of risk factors of breast cancer. (Table 3 )

\section{Discussion}

Breast cancer is the commonest cancer in women both in the developed and the developing world. In most countries of the Association of South East Asia Nations (ASEAN), the burden of cancer is increasing due to population aging and growth, and the adoption of cancer-associated lifestyle behaviors. Identification of breast cancer at an early stage is important in improving breast cancer outcome. A community-based cross-sectional study carried out in Yangon found that $40 \%$ of the respondents agreed that breast lump(s) are a condition that could further develop into breast cancer. Also, the majority (93\%) agreed that breast self-examination should be carried out to detect breast cancer. More than half $(56 \%)$ of

Table 2. Awareness of signs of breast cancer, risk factors and breast cancer screening by the study participant age groups

\begin{tabular}{|c|c|c|c|}
\hline Variables & $\begin{array}{c}\text { Age } 18-39 \\
\text { years }(\mathrm{N}=341)\end{array}$ & $\begin{array}{c}\text { Age }>40 \\
\text { years }(\mathrm{N}=61)\end{array}$ & $\begin{array}{c}\text { Chi-square } \\
\text { P value }\end{array}$ \\
\hline \multicolumn{4}{|l|}{ Signs of breast cancer } \\
\hline Lump in breast & $222(65.1)$ & $43(70.5)$ & NS \\
\hline Thickening of the skin of breast & $85(25.4)$ & $18(29.5)$ & NS \\
\hline Swelling of the breast & $86(25.4)$ & $12(19.7)$ & NS \\
\hline Dimpling of the skin of the breast & $98(29.3)$ & $21(34.4)$ & NS \\
\hline Redness of the skin of the breast & $66(19.6)$ & $17(18.0)$ & NS \\
\hline Soreness of the breast & $67(19.8)$ & $14(23.3)$ & NS \\
\hline Change of breast shape & $129(39.9)$ & $33(54.1)$ & $* 0.033$ \\
\hline Discharge from nipple & $113(33.4)$ & $30(49.2)$ & $* 0.021$ \\
\hline \multicolumn{4}{|l|}{ Risk Factors } \\
\hline Breast lumps increase risk & $157(46.3)$ & $36(59.6)$ & $* 0.046$ \\
\hline Breast cancer history in family increases risk & $178(52.4)$ & $37(61.7)$ & NS \\
\hline Oral contraceptives increases risk & $41(12.1)$ & $7(11.5)$ & NS \\
\hline No breast feeding increases risk & $142(46.8)$ & $23(44.3)$ & NS \\
\hline Nulliparity increase risk & $162(47.3)$ & $34(55.9)$ & NS \\
\hline \multicolumn{4}{|l|}{ Screening } \\
\hline Heard of Breast Cancer Screening & $226(66.9)$ & $32(53.5)$ & NS \\
\hline Heard of Breast Self-Examination & $184(55.4)$ & $34(55.7)$ & NS \\
\hline Heard of Mammography & $92(27.1)$ & $10(16.7)$ & NS \\
\hline
\end{tabular}


Table 3. Awareness of signs of breast cancer, risk factors and breast cancer screening by level

\begin{tabular}{|c|c|c|c|}
\hline Variables & $\begin{array}{c}\text { Low (less than } \\
\text { high school) }(\mathrm{N}=282)\end{array}$ & $\begin{array}{l}\text { High (high school } \\
\text { and higher) }(\mathrm{N}=118)\end{array}$ & $\begin{array}{c}\text { Chi-square } \\
\text { P value }\end{array}$ \\
\hline \multicolumn{4}{|l|}{ Signs of breast cancer } \\
\hline Lump in breast & $179(63.5)$ & $85(72.0)$ & NS \\
\hline Thickening of the skin of breast & $57(20.4)$ & $46(39.3)$ & $* 0.000$ \\
\hline Swelling of the breast & $69(24.5)$ & $38(32.2)$ & NS \\
\hline Dimpling of the skin of the breast & $68(24.6)$ & $51(43.2)$ & $* 0.000$ \\
\hline Redness of the skin of the breast & $47(16.8)$ & $30(25.6)$ & NS \\
\hline Soreness of the breast & $53(19.0)$ & $28(23.7)$ & NS \\
\hline Change of breast shape & $99(35.2)$ & $62(52.5)$ & $* 0.001$ \\
\hline Discharge from nipple & $89(31.9)$ & $53(44.9)$ & $* 0.013$ \\
\hline \multicolumn{4}{|l|}{ Risk Factors } \\
\hline Breast lumps increase risk & 123(43.9) & $70(59.3)$ & *0.005 \\
\hline Breast cancer history in family increases risk & $136(48.6)$ & $77(65.3)$ & $* 0.002$ \\
\hline Oral contraceptives increases risk & $27(9.6)$ & $21(17.8)$ & $* 0.023$ \\
\hline No breast feeding increases risk & $99(35.4)$ & $69(58.5)$ & $* 0.000$ \\
\hline Nulliparity increase risk & $120(42.7)$ & 76 (64.4) & $* 0.000$ \\
\hline \multicolumn{4}{|l|}{ Screening } \\
\hline Heard of Breast Cancer Screening & $153(54.8)$ & $105(89.0)$ & $* 0.000$ \\
\hline Heard of Breast Self-Examination & $132(47.8)$ & $86(73.5)$ & $* 0.000$ \\
\hline Heard of Mammography & $167(59.2)$ & $45(38.1)$ & $* 0.000$ \\
\hline
\end{tabular}

the respondents thought that breast cancer is preventable. The findings highlighted the fact that prevention of breast cancer is recognized well by the participants. ${ }^{6}$ In the present study, a high proportion of the respondents $(65.9 \%)$ also acknowledged that breast lumps are an important sign of breast cancer. Moreover, a considerable proportion of the respondents $(40.4 \%)$ agreed that change in the shape of the breast is also an important sign of breast cancer.

The finding of low awareness levels of breast health, risk factors and breast cancer screening is in agreement with a study from Egypt where the authors reported that lowest levels of awareness were related to age, education and culture.' Awareness of breast cancer is important because it affects the likelihood that a woman will engage in appropriate preventive measures. The present study demonstrated that older women had significantly better awareness of two early breast cancer signs (change of breast shape and discharge from nipples) than their younger counterparts. They also knew the high risk of breast lumps better than their younger counterparts (59.0\% vs $46.3 \%)$. The higher degree of awareness among older women is an encouraging finding as older women above 40 years of age are at increased risk for breast cancer.

It is agreed upon that knowledge of breast cancer and the benefits of breast cancer screening are important in facilitating breast cancer screening behavior. ${ }^{10}$ Although breast cancer screening guidelines for women by different age-groups are well developed in developed countries, it is difficult for women in Myanmar to appreciate the risk and recognize the benefits of breast cancer screening. The main reason may be the often-asymptomatic behavior of the breast cancer in its early stages. In the present study, less than two-thirds of the participants (64\%) had heard of breast cancer screening. This is much lower than the study from Qatar where $90 \%$ of the subjects had heard of breast cancer screening. ${ }^{11}$
More importantly, a recent study on 248 nursing students in Myanmar revealed that only $60 \%$ of them had positive attitude towards breast cancer screening. Among them only $47 \%$ had the correct knowledge concerning breast self-examination and few practiced it regularly. ${ }^{12}$ The need for providing correct breast health and breast cancer screening techniques to the health care providers should be seriously considered for efficient transfer of information to the patients. A recent study also highlighted the need to provide proper health education on breast cancer and breast selfexamination to women residing in rural areas for early detection of breast cancer.

More information on the breast health and breast cancer screening among the basic health care personnel should be further explored for providing effective health education to the community. Improved awareness of breast health and breast selfexaminations could improve the breast selfexamination behavior and reduce the number of deaths from breast cancer. ${ }^{13}$ We found that nearly two-thirds of the participants reported awareness of lumps in the breast as a sign of breast cancer. A similar low level of awareness $(38.8 \%)$ was reported in a previous study carried out in Myanmar. ${ }^{6}$ Both studies concluded that awareness regarding lumps in breast should be increased. Globally, most commonly used breast cancer screening programs are Breast Self-Examination (BSE), Breast Clinical Examination (BCE), and mammography. Mammography is most effective but costly and accessibility is not easy for the general population. BSE could be the community-based screening method in Myanmar for the early detection of breast cancer. BCE could be introduced in secondary hospitals where specialist medical doctors are available. However, even in more developed countries, it has been suggested that identification of high-risk groups should be done incorporating breast 
cancer risk factors, breast cancer-related awareness and BSE practices, before referral to such centers. ${ }^{14}$ It has been suggested that cultural-appropriate strategies should be designed to promote breast cancer screening in the regions where ethnic groups with different characteristics reside. ${ }^{15}$ This could be a big challenge for a country like Myanmar where over 100 ethnic groups are widely dispersed throughout the country, especially in the hilly regions where health care infrastructure is weak. Mammograms are only recently available in two public tertiary hospitals for women and a few private hospitals in Myanmar, and its utilization is very limited. Almost $40 \%$ of women who came for mammogram to the Central Women Hospital in Yangon thought that it was very costly to have breast cancer screening. ${ }^{6}$ Thus, it will be difficult to use mammography as a screening tool for breast cancer in Myanmar.

Our study had some limitations. Although the questions were based on a previous study, some of the items were not specific enough to show correct awareness which underlines appropriate preventive and screening practice. For instance, $54.1 \%$ of respondents had heard of breast self-examination, but we do not know what the source of information had been and if the information was provided correctly.

As the study was hospital-based, the respondents were women seeking medical care for antenatal care or gynecological problems. Thus, their awareness about screening and signs of breast cancer might be potentially different from the general population. However, the study supported the fact that promotion of awareness of breast cancer through education is needed in Myanmar. Considering the findings from the present study, emphasis should be given to those with young age and to those with lower education as there was a marked contrast in the awareness of breast cancer and breast health among them as compared to those with older age and those with higher education. Awareness of lumps in breast should be increased. Awareness raising materials specifically targeted at them should be widely distributed in the community. Breast cancer screening guidelines should be developed and tested for application in the field situation. Recently, a "Breast Health Club" has been introduced in Myanmar with the aim of promoting awareness and action on breast health. ${ }^{16}$ Similar free-of-charge membership-based health clubs should be encouraged to promote community-based breast cancer educational programs in the country.

\section{Acknowledgements}

We would like to thank Professor Kyi Kyi Nyunt, Professor and Head of Obstetrics and Gynecology Department, University of Medicine (Mandalay) for supporting us to conduct this study.

\section{Conflict of Interest}

The authors declared no potential conflict of interests with respect to the research, authorship, and/or publication of this article. Also, the authors received no financial support for the research, authorship, and/or publication of this article.

\section{References}

1. World Health Organization. International Agency for Research on Cancer. 2020.

2. World Health Organization. Cancer Today, Data visualization tools for exploring the global cancer burden in 2020.2020.

3. Bray F, Ferlay J, Soerjomataram I, Siegel RL, Torre LA, Jemal A. Global cancer statistics 2018: GLOBOCAN estimates of incidence and mortality worldwide for 36 cancers in 185 countries. CA: a cancer journal for clinicians. 2018;68(6):394-424.

4. Kim Y, Yoo KY, Goodman MT. Differences in incidence, mortality and survival of breast cancer by regions and countries in Asia and contributing factors. Asian Pac J Cancer Prev. 2015;16(7):2857-70.

5. Thein H, Hlaing T, Myint TM. Risk Factors Of Breast Cancer In Burma. 1978.

6. Mon MM, Mon M, Than KK. Women's awareness, knowledge and perceived magnitude regarding common female cancers in Yangon, Myanmar. Asian Pac J Cancer Prev. 2009;10(6): 1047-50.

7. Myint NMM, Nursalam N, Has EMMa. Exploring the Influencing Factors on Breast SelfExamination Among Myanmar Women: A Qualitative Study. Jurnal Ners. 2020;15(1).

8. Parkin DM, Bray F, Ferlay J, Pisani P. Global cancer statistics, 2002. CA: a cancer journal for clinicians. 2005;55(2):74-108.

9. El-Shinawi M, Youssef A, Alsara M, Aly MK, Mostafa M, Yehia A, et al. Assessing the level of breast cancer awareness among recently diagnosed patients in Ain Shams University Hospital. The Breast. 2013;22(6):1210-4.

10. Bener A, El Ayoubi HR, Moore MA, Basha B, Joseph S, Chouchane L. Do we need to maximise the breast cancer screening awareness? Experience with an endogamous society with high fertility. Asian Pac J Cancer Prev. 2009;10(4):599-604.

11. Donnelly TT, Al Khater A-H, Al-Bader SB, Al Kuwari MG, Malik M, Al-Meer N, et al. Factors that influence awareness of breast cancer screening among Arab women in Qatar: results from a cross sectional survey. Asian Pacific Journal of Cancer Prevention. 2015;15(23): 10157-64.

12. Aye TT, Mon S. Knowledge, attitude and prevention practice about breast cancer among female nursing students in University of Nursing 
(Yangon), Myanmar. 2021.

13. Khiyali Z, Aliyan F, Kashfi SH, Mansourian M, Khani Jeihooni A. Educational Intervention on Breast Self-Examination Behavior in Women Referred to Health Centers: Application of Health Belief Model. Asian Pac J Cancer Prev. 2017;18(10):2833-8.

14. Lee CY, Kim HS, Ham O. Knowledge, practice, and risk of breast cancer among rural women in Korea. Nursing \& Health Sciences. 2000;2(4):225-30.

15. Wu T-Y, West B, Chen Y-W, Hergert C. Health beliefs and practices related to breast cancer screening in Filipino, Chinese and Asian-Indian women. Cancer detection and prevention. 2006;30(1):58-66.

16. Soe YSY, Win Z, Aung T, Win T, Htun Y. "You Can Breast Health Club" Empowering Healthy Women of Myanmar to Enhance Breast Cancer Awareness and Take Action. American Society of Clinical Oncology; 2018; 4(2): 4:126. 